\title{
Energy Performance Modeling of a Sugar Manufacturing Industry
}

\author{
${ }^{*}$ Olasunkanmi O. Akinyemi and Olusesi A. Oladunjoye \\ Department of Mechanical Engineering, \\ Faculty of Engineering, \\ Olabisi Onabanjo University, \\ Ago-Iwoye, Nigeria
}

E-mail: ooakinyemi@oouagoiwoye.edu.ng

\begin{abstract}
Effective energy monitoring, reporting, and management strategies for wise energy usage is one of the objectives of Energy Management. Numerous researches have highlighted the extremely good profits of imposing business and industrial energy management measures. Notably, a number of those research display that extra financial savings may be found out in growing international locations. Unfortunately, industries in developing countries like Nigeria are lagging behind in the adoption of energy management measures and as such missing the benefits of implementation. This research study sets out to evaluate the energy consumption performance in manufacturing industry in order to showcase the gains of energy management in manufacturing industry. Data on weekly energy consumption (in MW) and weekly production of sugar (in Bags, $50 \mathrm{~kg} / \mathrm{bag}$ ) were obtained from a sugar manufacturing company in southwestern Nigeria. Energy management data analysis and modeling was done using linear regression plot of energy consumption against production; energy intensity plot and cumulative sum of difference (CUSUM) plot respectively. The energy performance model was obtained from the linear regression plot and two parameters namely incremental energy consumed per bag (per $\mathrm{kg}$ ) of sugar produced and "no-production" energy consumption are the performance measures. The model showed that the incremental energy consumed per bag (or per $\mathrm{kg}$ ) is $0.00008 \mathrm{MW} / \mathrm{Bag}$ or $80 \mathrm{~W} / \mathrm{Bag}$ or $1600 \mathrm{~W} / \mathrm{kg}$ while the no-production energy consumption is 211.73 MW. Results also reveals that the no-production activities consumed energy more when compared with the actual energy used for production. CUSUM identified five periods when energy consumption gave higher and increased production thereby showing that CUSUM charts are more effective in detecting changes in energy consumption. The research study has shown how energy management data analysis can be helpful in taking decision that will enhance increased production and reduction of no-production energy consumption activities.
\end{abstract}

Keywords: Energy management, CUSUM, Performance model, Energy, No-production energy consumption

\section{INTRODUCTION}

Energy (which exist in various forms namely work, heat, radiation, gravitational (potential) energy, nuclear energy, solar energy, chemical energy and electric energy (electricity)) is essential for the creation of wealth and improvement of social welfare; this means that adequate and reliable supply of energy is required to ensure sustainable development. 
However, the use and conversion of primary energy most of the time results in waste and emission; they are harnessed from limited resources which are considered environmentally unsustainable. To achieve this requires the judicious use of resources, technology, appropriate incentives and strategic policy planning. Two concepts have been used to achieve judicious use of energy resources and technology namely energy management and energy efficiency. Whilst Energy management refers to the strategy of adjusting and optimizing energy, using systems and procedures so as to reduce energy requirements per unit of output while holding constant or reducing total costs of producing the output from these systems (Lujia, 2016); energy efficiency basically refers to the reduction of energy input for a given service, goods or output.

Energy monitoring, target setting, and reporting (MT\&R) is one of the activities used to achieve these two concepts. Monitoring is the everyday series of statistics on energy use. Its cause is to set up a foundation of management control, to decide whilst and why energy intake is deviating from a longtime sample, and as a foundation for taking management decision wherein necessary. Monitoring is basically geared toward retaining a longtime sample of energy usage. The critical question from a monitoring point of view is, why, for the same level of production, do points A and B have quite different energy consumption? What we need is some means of sorting this out; the technique that does this is called Cumulative Sum of difference (CUSUM) analysis. CUSUM is a powerful technique for developing management information regarding the energy performance of a plant, or an energy-consuming system e.g. oven or furnace. It distinguishes between significant events affecting performance namely faults or improvements and noise. Its output indicates energy intensities and energy consumption patterns which are indicators to adopting and developing energy efficient technologies and management strategies.

A number of studies have focused on energy management and energy performance modeling of manufacturing industry. Puranik (2007) highlighted the benefits of CUSUM charts for monitoring energy use performance for a melting section of a Foundry Company in India. The study shows that CUSUM charts are more effective in detecting changes in energy use than the traditional Statistical Control Charts. Taner et al., (2018) used CUSUM to compare the performance of energy consumption in a sugar manufacturing company over a 4 year period (on a yearly basis). The study revealed the base year period (good performance of energy consumed) and the year with the worst performance of energy consumed. Hasan and Trianni (2020) reviewed energy management assessment models for industrial energy efficiency. The assessment models reviewed are the minimum requirements model, maturity model, energy management matrix model, and energy efficiency measures characterization framework respectively. Lujia (2016) worked on systematic modeling of manufacturing energy use, consumption forecasting, and supply optimization. The study reveals the increase in the understanding of energy usage in the manufacturing system and the improvements the awareness of the importance of energy conservation and environmental protection brings to bare. Ototo (2021) studied the effect of renewable energy consumption on manufacturing sector and evaluate effect of nonrenewable energy consumption on manufacturing sector and decompose the effect of energy consumption on performance.

Furthermore, discrete event simulation (DES) modeling have been used extensively for manufacturing energy performance modeling namely Solding and Thollander (2006) investigated the electrical energy consumption of an iron foundry through the use of DES simulation, with the aim to combine material flow analysis with energy and resource flows; Seow and Rahimifard (2011) presented a framework of modeling energy flows within 
manufacturing using indirect and direct energy consumption data to provide a breakdown of energy used during production of a single product, the embodied product energy (EPE), through the use of DES and a recent study by Rodrigues et al., (2018) proposes a method of analysing electrical energy consumption in manufacturing processes, both the complete process or part of. Other research work in this area includes those of Keshari et al., (2018), Prabhu and Taisch (2019), Mousavi et al., (2016), Kohl (2014) and Cataldo et al., (2019).

The use of CUSUM methodology for energy consumption monitoring and performance is not popular amongst manufacturing industry in Nigeria as its use is rarely reported or scarce as evident in the literature. Therefore, this research study aim to establish the use of cumulative sum of differences (CUSUM) to evaluate the performance of energy consumption in a sugar manufacturing industry in Southwest Nigeria.

\section{METHODOLOGY}

\section{Developing the Energy Performance Model}

The methodology involve the plot of energy consumption and production graph, the derivation of the general form of equation of the line using regression analysis (equations 1 and 2) and the formulation of CUSUM plot. Then the implementation of the method will be illustrated by a case study (Puranik, 2007).

Or

$$
y=m x+c
$$

$$
\text { Energy }=\text { slope } \times \text { production }+ \text { intercept }
$$

Where c, the intercept (and, no load or zero production energy consumption), and $\mathrm{m}$, the slope, is the empirical coefficient, characteristic of the system being analysed. While there are actually conditions in which this linear model is inappropriate, and both a multivariate courting exists (manufacturing and weather, for example), or non-linear features enter the model, this courting serves nicely withinside the large majority of cases.

\section{Plot energy consumption against production}

The first step in the analysis process is to determine the functional relationship between energy consumption and production (using Statistical package SPSS), a relationship of the form of Equation 1.

\section{Determine the base-line relationship}

The determination of a suitable baseline often is an iterative process in which the baseline regression - CUSUM sequence is repeated until a useful analysis emerges. However, knowledge of the plant circumstances can often point to a particular period as performing consistently, the main criterion for a useful baseline. That is, if it is known that no improvements that relate to energy efficiency were made, and no malfunctions occurred (control system problems, for example), and the production rate was typical for the plant, then that period will probably serve as a good baseline. For this research work; each immediate past monthly energy data serves as the energy data for the baseline period.

\section{Carry out Cumulative Sum of Differences (CUSUM) analysis}

CUSUM is a powerful technique for developing management information regarding the energy performance of a plant, or an energy-consuming system such as an oven or furnace, for example. It distinguishes between significant events affecting performance - faults or improvements - and noise. CUSUM stands for 'CUmulative SUM of differences', where 'difference' refers to differences between the actual consumption and the consumption you 
expect on the basis of some established pattern - what we have called the energy performance model. If consumption continues to follow the established pattern, the differences between the actual consumption and the established pattern will be small and randomly either positive or negative. The cumulative sum of these differences over time, CUSUM, will stay near zero. Once a change in pattern occurs due to the presence of a fault or to some improvement in the process being monitored, the distribution of the differences about zero becomes less symmetrical and their cumulative sum, CUSUM, increases or decreases with time. The CUSUM graph therefore consists of straight sections separated by kinks; each kink is associated with a change in pattern, each straight section is associated with a time when the pattern is stable.

\section{i. Calculate the CUSUM}

The baseline relationship is used to calculate anticipated energy consumption for any given production level. It is the distinction among this and the real value that is crucial on this analysis. The overall energy performance advanced is used to calculate an expected consumption for every week via way of means of substituting the production for that week withinside the formula.

Subtract the actual consumption from the predicted consumption for each week to find the difference. Add the difference up for all the weeks/months/years up to the present to obtain CUSUM. A plot of CUSUM against time is then produced.

\section{ii. Interpret the CUSUM Graph}

The crucial factors at the CUSUM graph are evaluated to decide wherein there are adjustments in slope of the line. These can be easily done, and more precisely located by laying straight lines over the more or much less consistent slope sections of the plotted graph in 3(i) above.

\section{Case Study}

In a sugar manufacturing industry, energy is used for generating power and process operation. Process operation is the application of steam as a form of heat for agitating the molecules of slurry, liquor, massecuite and syrup in process house so that the end product which is granulated white sugar could be achieved. The case study sugar manufacturing industry is Dangote Sugar Refinery; located in Lagos Southwest Nigeria

Energy is being generated from steam boilers fired by natural gas supplied from Nigeria Gas Company at a given rate. The case study sugar manufacturing industry has six steam boilers; namely:

i. Boilers \#1and \#3 which has a capacity is 40 tons/hr., its working pressure is 21 bar with each of them having a working temperature of $300^{\circ} \mathrm{C}$.

ii. Boilers \#4 and \#5 which has a capacity of 80tons/hr., its working pressure is 21 bar with each of them having an operating temperature of $300^{\circ} \mathrm{C}$.

iii. Boilers \#6 and \#7 which has a capacity of 100tons/hr., its working pressure 21bar with each of them having an operating temperature of $300^{\circ} \mathrm{C}$.

Number of boilers fired while on operation is a reflection of the desired production output of the company. Not all the boilers are put on line while on operation. While on full scale operation, a maximum of three boilers are fired. This gives rise to the generation of steam of which it first point of call is Power house section. At this section, dry heat in form of steam is passed into the turbine in order to run the prime movers and rotor blades. This give rise to the generation of electric power in the plant and exhaust steam from the turbine is passed down to process house for operational activities. Alternatively, dry steam could be supplied 
directly to process house form boiler house if the supply of exhaust steam from power house is not sufficient.

Process house are subdivided into three sections namely affination and clarification section; decolonization section and crystallization section (i.e. centrifuge and drying section). These sections are expected to be incorporated with a flow meter for the recording of steam consumption. It ascertains if energy generated is effectively utilized. The refinery which comprises of the boiler section, water treatment plant and equipment in process house consumes the power generated from the power house. On a daily basis the voltage consumed is computed and are converted to power by multiplying it by 0.0152 . The formula used for getting the power consumed is given in equation 3 :

$$
\text { Power consumption }(\mathrm{KW})=\frac{\sqrt{3} \mathrm{VI} \cos \varphi}{1000} \times \text { Time }(24 \mathrm{hrs})
$$

Where KW = kilowatts, $\mathrm{V}=$ Voltage, $\mathrm{I}=$ Current in ampere, $\mathrm{A}$ and Cos $\varnothing=$ Power Factor.

\section{Data Collection}

The weekly energy consumption and production information was obtained from the chat of energy consumption in the case study manufacturing industry; Dangote Sugar Refinery, Lagos State Southwest Nigeria. The data were collected from January 2021 - June 2021 as shown in Table 1 below.

\section{RESULTS AND DISCUSSION}

\section{Energy Performance model}

Figure 1 is showing a scatter plot of the energy consumption - production data and Figure 2 is showing the plot of energy intensity - time (weeks) respectively. From Figure 1, a linear regression model which is the energy performance model is obtained as shown in equation 4:

Weekly Energy Consumption (MW)

$$
=0.00008 \times \text { Weekly Production }(\text { Bag })+211.73 \ldots
$$

From equation 3 the energy consumption parameters or characteristics for a sugar manufacturing industry are stated as follows:

i. The slope, 0.00008 , represents the incremental energy consumed (MW) per bag of sugar produced; and

ii. The energy consumption axis intercept, $211.73 \mathrm{MW}$, represents the "noproduction" energy consumption, or base load.

The bodily importance of those parameters is vital to an expertise of the way energy is consumed in a sugar production industry, and in which efficiencies can be found. It is especially vital to apprehend that common energy intensity - on this case, MW/bag as proven in Figure 2 - is a very rough indicator of performance only because it is a value that inevitably will decrease as production increases due to the fact that the base load is being unfold over extra production. 
Table 1: Weekly Energy consumption in a Sugar Manufacturing Industry

\begin{tabular}{cccc}
\hline Week & Energy Consumption (MW) & $\begin{array}{c}\text { Specific Energy Consumption } \\
\text { (MW/bag) }\end{array}$ & Production (bag) \\
\hline 1 & 242.4 & 680.1 & 356412 \\
2 & 243.7 & 757.4 & 321774 \\
3 & 241.9 & 782.2 & 309274 \\
4 & 243.4 & 779.1 & 312422 \\
5 & 240.9 & 1196.4 & 201362 \\
6 & 243.8 & 765.1 & 318631 \\
7 & 228 & 680.3 & 335139 \\
8 & 246 & 789.0 & 311806 \\
9 & 212.8 & 1272.0 & 167293 \\
10 & 214.1 & 627.9 & 340985 \\
11 & 232.9 & 1176.1 & 198019 \\
12 & 245.1 & 946.8 & 258873 \\
13 & 233 & 812.2 & 286860 \\
14 & 245.2 & 868.3 & 282400 \\
15 & 242 & 806.4 & 300087 \\
16 & 244.9 & 804.9 & 304253 \\
17 & 235.5 & 799.7 & 294503 \\
18 & 211 & 846.3 & 249314 \\
19 & 207.5 & 696.3 & 297993 \\
20 & 208.9 & 667.3 & 313051 \\
21 & 232.4 & 703.1 & 330540 \\
22 & 222.2 & 746.2 & 297777 \\
23 & 249.5 & 717.4 & 347780 \\
24 & 224.4 & 654.4 & 342910 \\
25 & 232.4 & 719.4 & 323050 \\
26 & 271.3 & 808.8 & 335450 \\
\hline
\end{tabular}

Table 2 shows the CUSUM energy consumption data for the case study. This is obtained by first using the energy performance model to predict the energy consumption for each production. The predicted energy consumption data are now subtracted from the actual data; this gives the difference of the energy consumption data. CUSUM data were obtained by adding energy consumption data cumulatively.

The important factors at the CUSUM graph as proven in Figure 3 are the changes in slope of the line. These may be effortlessly seen, and extra exactly placed with the aid of using laying straight lines over the more or much less regular slope sections. We see that those slope changes took place at weeks 4, 5, 6, 7, 8, 12, 13, 16, 17, 22, 23 and 25. More especially in terms of the manufacturing system being analysed, the graph indicates:

i. There had been five measures to lessen energy consumption; the first measure took effect in week 6 and the energy consumption measure taken lasted for only 2 weeks.

ii. The second measure took effect in week 8 and the energy consumption measure taken lasted for only 3 weeks.

iii. The third measure took effect in week 12 and the energy consumption measure taken lasted for only 2 weeks. 
iv. The fourth measure took effect in week 17 and the energy consumption measure taken lasted for 7 weeks.

v. The fifth measure took effect in week 23 and the energy consumption measure taken lasted for only 3 weeks.

Table 2: CUSUM Energy Consumption data for a Sugar Manufacturing Company

\begin{tabular}{ccccc}
\hline Week & $\begin{array}{c}\text { Energy Consumption } \\
\text { (MW) }\end{array}$ & $\begin{array}{c}\text { Predicted Energy } \\
\text { Consumption (MW) }\end{array}$ & $\begin{array}{c}\text { Difference (MW) } \\
\text { CUSUM } \\
\text { (MW) }\end{array}$ & $\begin{array}{c}\text { (MW } \\
2\end{array}$ \\
242.4 & 240.2 & 2.2 & 8.4 \\
3 & 243.7 & 237.5 & 6.2 & 13.8 \\
4 & 241.9 & 236.5 & 5.4 & 20.5 \\
5 & 243.4 & 236.7 & 6.7 & 33.6 \\
6 & 240.9 & 227.8 & 13.1 & 40.1 \\
7 & 243.8 & 237.2 & 6.6 & 29.6 \\
8 & 228 & 238.5 & -10.5 & 38.9 \\
9 & 246 & 236.7 & 9.3 & 26.6 \\
10 & 212.8 & 225.1 & -12.3 & 1.7 \\
11 & 214.1 & 239.0 & -24.9 & 7.0 \\
12 & 232.9 & 227.6 & 5.3 & 19.7 \\
13 & 245.1 & 232.4 & 12.7 & 18.0 \\
14 & 233 & 234.7 & -1.7 & 28.9 \\
15 & 245.2 & 234.3 & 10.9 & 35.1 \\
16 & 242 & 235.7 & 6.3 & 44.0 \\
17 & 244.9 & 236.1 & 8.8 & 44.2 \\
18 & 235.5 & 235.3 & 0.2 & 23.5 \\
19 & 211 & 231.7 & -20.7 & -4.6 \\
20 & 207.5 & 235.6 & -28.1 & -32.4 \\
21 & 208.9 & 236.8 & -27.9 & -38.2 \\
22 & 232.4 & 238.2 & -5.8 & -51.6 \\
23 & 222.2 & 235.6 & -13.4 & -41.6 \\
24 & 249.5 & 239.6 & -14.9 & -56.4 \\
25 & 224.4 & 239.2 & -5.2 & -61.6 \\
26 & 232.4 & 237.6 & 32.7 & -28.8 \\
\hline
\end{tabular}

\section{DISCUSSION}

This research study models the energy performance for a sugar manufacturing company. Figure 1 shows the linear regression plot of weekly energy consumption (MW) against the weekly production of sugar (in bags).The plot showed an increasing trend i.e. as the energy consumption increase; the production also increases. This plot was used to develop the energy performance model as shown in equation 4 . Two parameters of note emanated from the model namely incremental energy consumed per bag of sugar produced and the "noproduction" energy consumption. The incremental energy consumed per bag is 0.00008 $\mathrm{MW} / \mathrm{Bag}$ or $80 \mathrm{~W} / \mathrm{Bag}$ or $1600 \mathrm{~W} / \mathrm{kg}$ (a bag weighs $50 \mathrm{~kg}$ ); while the no-production energy consumption is $211.73 \mathrm{MW}$. The model reveals that much of the energy consumed in this Case Study Company goes mostly to no production activities. 


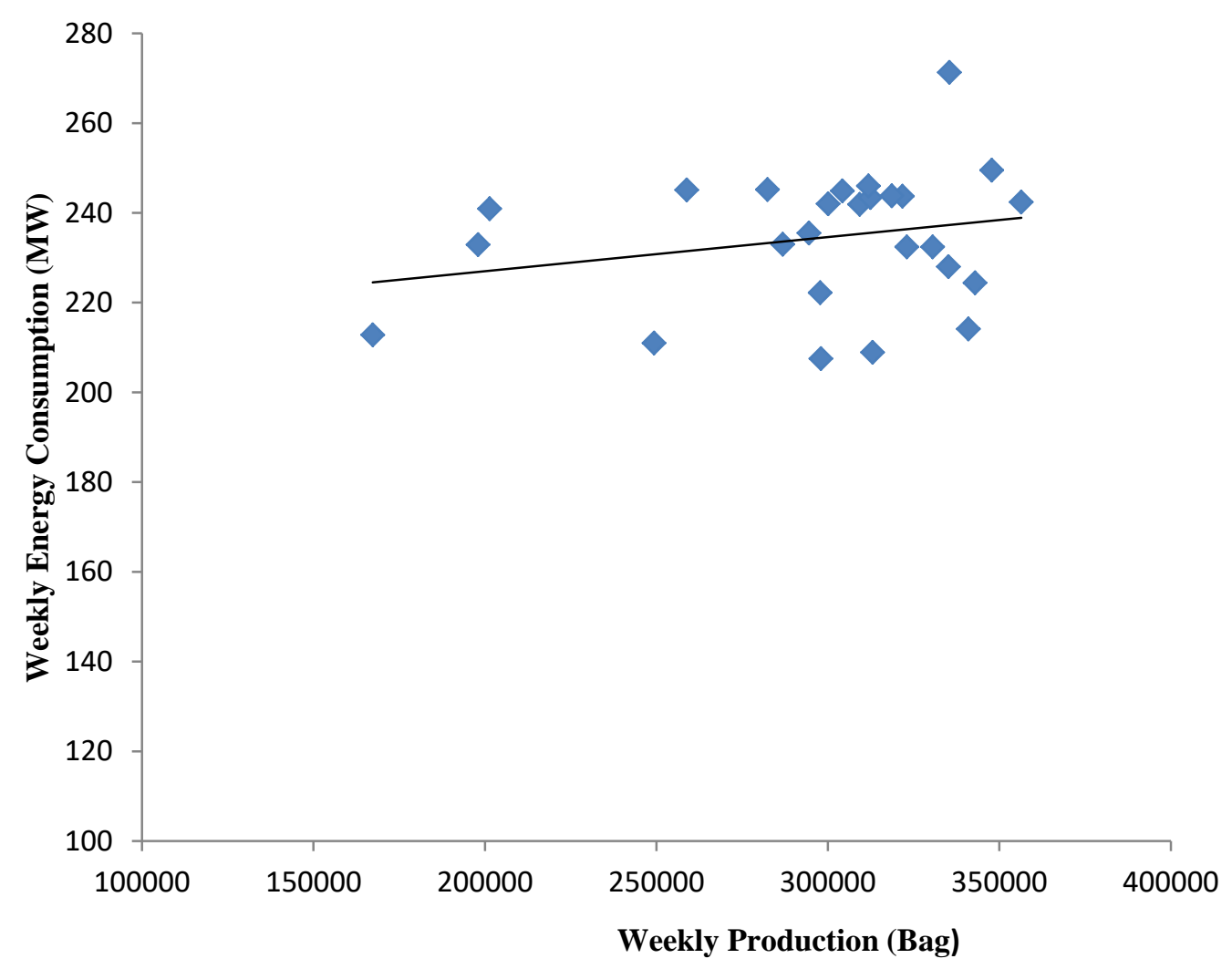

Figure 1: Linear Regression of Entire Data Set

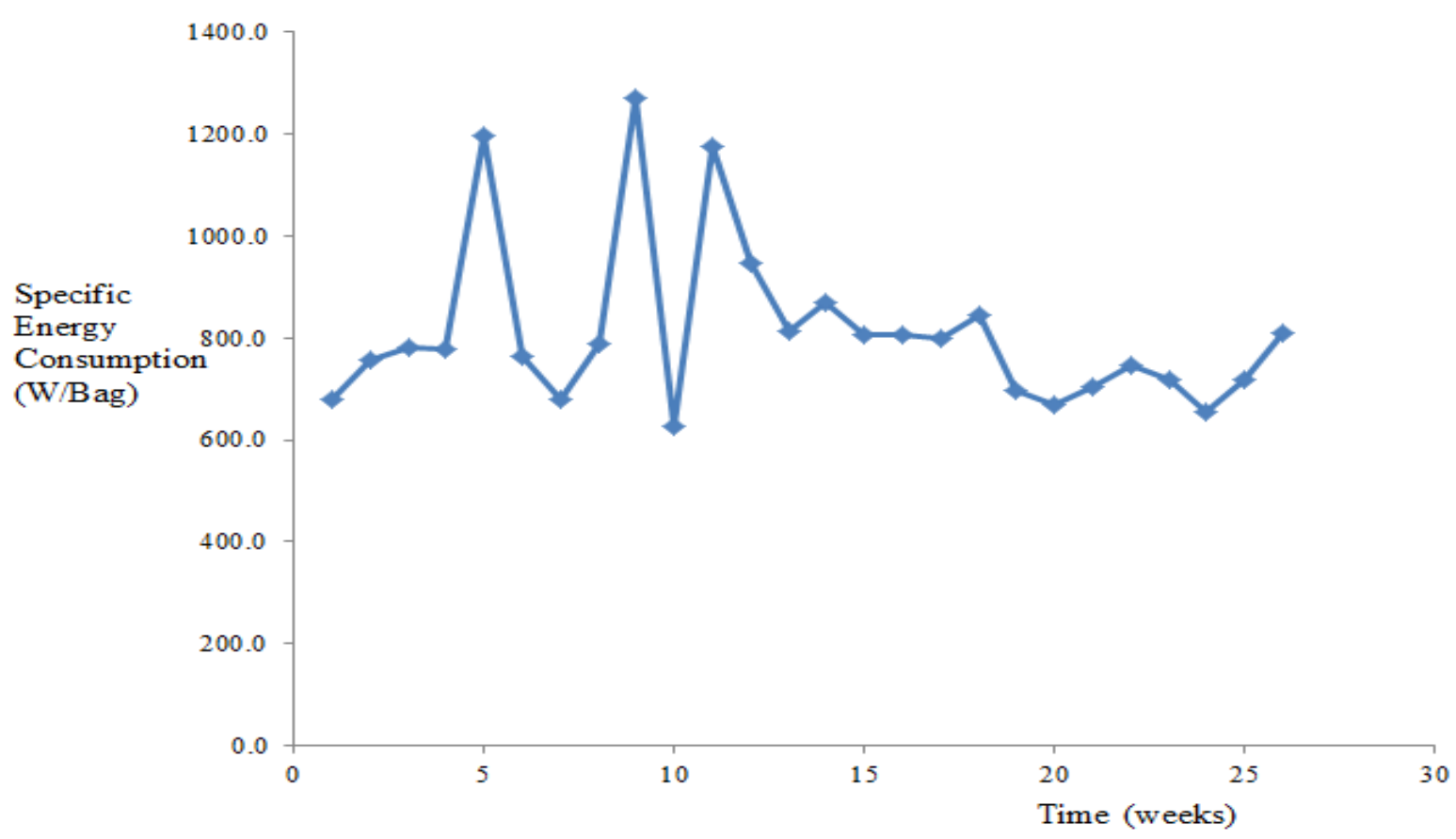

Figure 2: Energy Intensity Time Series Plot 


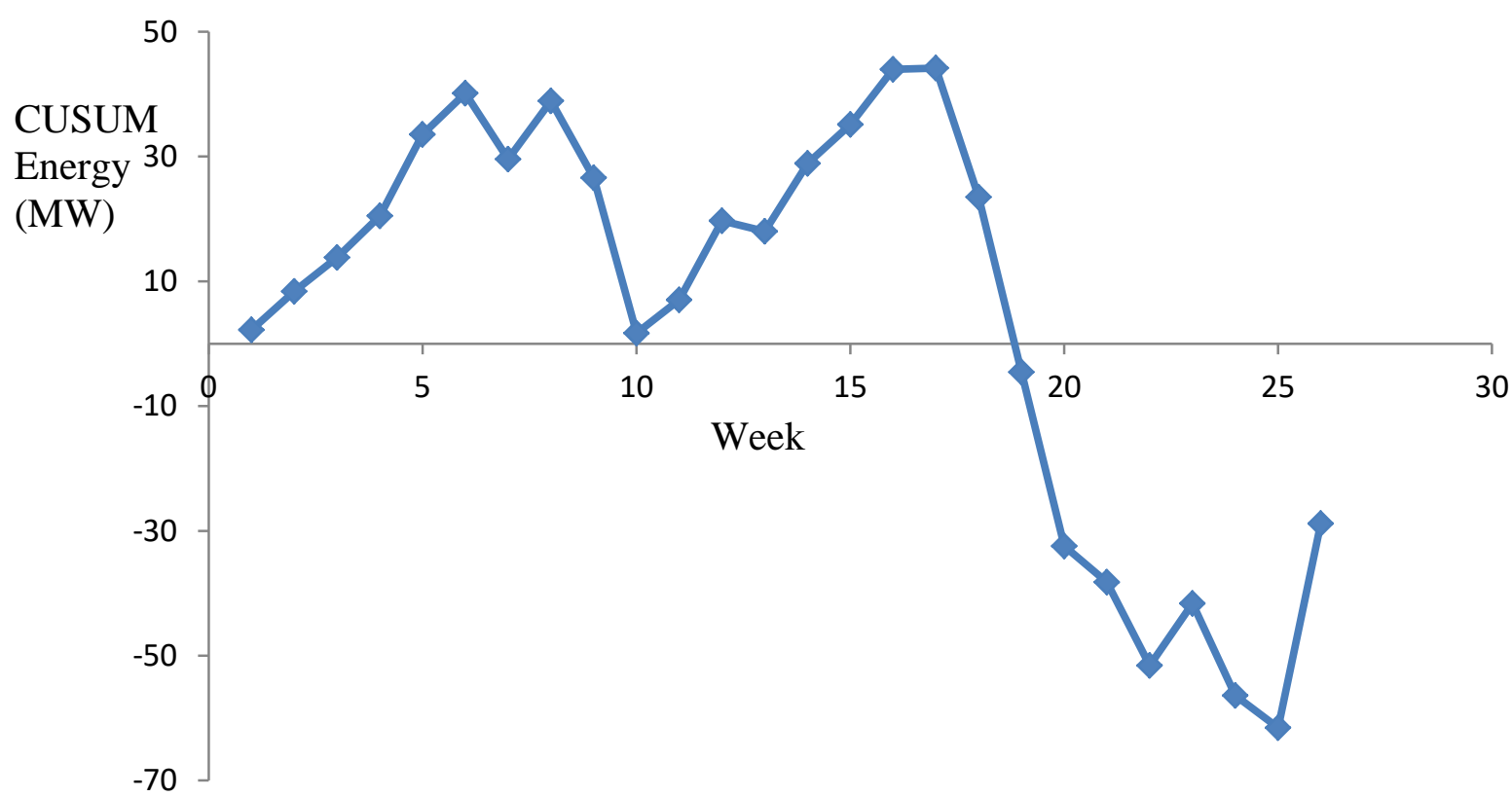

Figure 3: CUSUM Graph for the Sugar Manufacturing Company

Figure 2 showed the plot of energy intensity for sugar manufacturing company. It should be noted that the value of energy intensity decreases as the production increases. During the twenty-six weeks energy performance analysis, production of sugar manufactured increases six times namely between the $5^{\text {th }}$ week and $7^{\text {th }}$ week (2weeks), $9^{\text {th }}$ week and $10^{\text {th }}$ week $(1$ week), $11^{\text {th }}$ week and $13^{\text {th }}$ week ( 2 weeks), $14^{\text {th }}$ week and $17^{\text {th }}$ week ( 3 weeks), $18^{\text {th }}$ week and $20^{\text {th }}$ week ( 2 weeks) and $22^{\text {nd }}$ week and $24^{\text {th }}$ week ( 2 weeks) respectively. This clearly shows that there were 10 weeks when the energy consumed gave a satisfactorily good performance. The energy intensity value also revealed how lower energy consumed gave a higher production while a higher energy consumed gave a lower production. This can be seen in Table 2 and as stated in the six times increase in the production of sugar.

The cumulative sum of difference (CUSIM) plot, Figure 3 confirmed the analysis of the energy intensity plot. CUSUM is more specific in its analysis as it detects changes in energy consumption and production (Puranik, 2007). CUSUM revealed periods when the energy consumption gives good performance and otherwise. These periods with good performance identified culminated in less energy consumption and increased production whilst periods with poor performance will require the energy manager to respond proactively in order to control the situation and resolve the problem. The result of this research study is similar to work done by Puranik (2007) for a melting section of a Foundry and Taner et al., (2018) for a sugar manufacturing company in Turkey. It should be noted that energy consumption of manufacturing industry need to be analyse yearly so that this will give the management; information on the performance of energy consumed (Taner et al., 2018).

\section{CONCLUSION}

The importance of energy management, commitment and strategy for continuous improvement in manufacturing industry is inevitable. This research study report the methodology for energy management data analysis and the performance modeling of energy consumption in a sugar manufacturing industry. The energy performance model reveals two parameters namely incremental energy consumed per bag of sugar produced and the "no-production" energy consumption. The energy consumed per bag is 0.00008 
MW/Bag or $80 \mathrm{~W} / \mathrm{Bag}$ or $1600 \mathrm{~W} / \mathrm{kg}$ (a bag weighs $50 \mathrm{~kg}$ ); while the no-production energy consumption is $211.73 \mathrm{MW}$. The study also reveals that the no-production activities consumed energy more when compared with the actual energy used production. Further analysis of energy consumption was done using CUSUM and this reveal periods when energy consumption gave good and poor performance.

\section{ACKNOWLEDGEMENT}

The authors express their appreciation to the Energy Manager of Dangote Sugar Refinery, Apapa Lagos for extending all their support to carry out this research study.

\section{REFERENCES}

Cataldo A, Scattolini R and Tolio T. (2015). An energy consumption evaluation methodology for a manufacturing plant. CIRP Journal of Manufacturing Science and Technology. 11:53-61.

Hasan A. S. M.M. and Trianni A. (2020). A Review of Energy Management Assessment Models for Industrial Energy Efficiency. Energies2020,13, 5713; doi:10.3390/en13215713.

Keshari A, Sonsale A. N., Sharma B. K. and Pohekar S. D. (2018). Discrete event simulation approach or energy efficient resource management in paper and pulp industry. Procedia CIRP. 78:2-7.

Kohl J, Spreng S and Franke J. (2014). Discrete event simulation of individual energy consumption for product varieties. Procedia CIRP 2014.

Lujia, F. (2016). Manufacturing System Energy Modeling and Optimization. All Dissertations. 1648. https://tigerprints.clemson.edu/all_dissertations/1648.

Mousavi S, Thiede S, Li W, Kara S and Herrmann C. (2016). An integrated approach for improving energy efficiency of manufacturing process chains. Internal Journal of Sustainable Engineering.

Ototo E. G. (2021). Energy Consumption and Performance of Manufacturing Sector in Kenya. IOSR Journal of Economics and Finance (IOSR-JEF), e-ISSN: 2321-5933, p-ISSN: 2321-5925. 12 (1) Ser. I (Jan. -Feb. 2021): 23-36.

Prabhu V. V. and Taisch M. (2019). Simulation Modeling of Energy Dynamics in Discrete Manufacturing Systems vol. 45. 2019. 6. IFAC, 23AD.

Puranik V.S. (2007). CUSUM Quality Control Chart for Monitoring Energy Use Performance. Proceedings of the 2007 IEEE IEEM. 1-4244-1529-2/07/\$25.00 @2007 IEEE. Pp.: 12311235.

Rodrigues G. S., Espíndola Ferreira J. C. and Rocha C. R. (2018). A novel method for analysis and optimization of electric energy consumption in manufacturing processes. Procedia Manufacturing. 17:1073-81.

Seow Y and Rahimifard S. (2011). A framework for modeling energy consumption within manufacturing systems. CIRP Journal of Manufacturing Science and Technology. 4(3):258-64.

Solding and Tholander. (2006). Increased energy efficiency in a Swedish iron foundry through use of discrete event simulation. Proceedings of the Winter Simulation Conference. pp. 1971-6.

Taner T, Sivrioglu M, Topal H, Ahmet S.D. and Wongwises S. (2018). A model of energy management analysis, case study of a sugar factory in Turkey. Sådhanå (2018) 43:42. Indian Academy of Sciences https://doi.org/10.1007/s12046-018-0793-2 